\title{
Problems and solutions during the process of university's graduation project for young teachers
}

\author{
Zhaojie Shen ${ }^{1, a,{ }^{*}}$, Wenzheng $\mathrm{Cui}^{1}$ \\ ${ }^{1}$ School of Automotive Engineering, Harbin Institute of Technology (Weihai), Weihai, 264209, China \\ aemail: shenzj@hit.edu.cn \\ *corresponding author
}

Keywords: Graduate Design; Relationship between Teacher and Student; Young Teacher; Micro Class

\begin{abstract}
The graduation project is the final stage of university education for college students. Young teachers always feel difficult during this process. This paper will give some suggestions of young teacher during the process of graduation design on how to overcome their shortages such as lack of experiences, poor communication skills, and lack of knowledge. Young teaches should progress together with students, and use proper methods to ask questions to eliminate mistrust. Micro lesson can build a vivid teaching situation and injects new vitality to the teaching. Combining micro lesson method and traditional teaching resources, the teaching result of car engine principle can be improved effectively.
\end{abstract}

\section{Introduction}

The final stage of university education for college students is the graduation project, it is the most effective and comprehensive way to test four years university education both in knowledge and practical ability. In Chinese university, there is a mentor for each students, who determines graduation research project, and guides them finish the project through three stages. The first stage is feasibility and significance survey to raise the issue and propose the solution of this issue, the second stage is implementation phase to solve the issue, the last stage is to assess completion and pros and cons of the graduation research project. In all these stages, the mentor should be readily available when students encounter difficulties. One crucial factor for successful graduation is the relationship between several students and one teacher especially for young teachers. They are always confronted with more obstacles during the graduation project than older teachers because of lack of experience and poor communication skills and so on. They always face challenges to build trust between students and themselves.

To improve the quality of graduate design, Li and coworkers [1] proposed to build campus and enterprise cooperation instructor team, establish a virtual campus internships auxiliary production platform, it will enhance students' engineering practice ability. Stocking and coworkers [2,3] in Cranfield University proposed to teaching aircraft design by providing practical experience. They give 70 students an opportunity to design a major part of aircraft for three years let them attend lecture modules, perform a piece of individual research and work on a group design project. Zhou and coworkers [4] reviewed some problems in the process of graduation design, they pointed out that graduation design is an important part which could improve students' comprehensive training, practice ability and innovation spirit, the teachers and the students should keep proper attitude during this process.

In this paper, I would like to share some other views come from my own experiences as a yong teacher, and give some corresponding suggestions and measures for improvement of graduation project.

\section{Progress Together with Students}

As a young teacher, I have advised 15 undergraduate students for two years. As lack of 
experience to guide students, I tried to give them enough room to select topics they are interested in and I didn't specified research content except those who is with difficulties in selecting their own graduate project. Students were required to work independently to survey both online and library, they were also allowed to contact enterprise engineers, after that I will give them a table to answer some questions. These questions were used to test if the research topic is appropriate for graduation design. First to describe the scientific or technical issue you want to solve. Second to survey the backgrounds of your scientific or technical issue, it should be clear about what are the disadvantages of current technologies. In response to these shortcomings explain the purpose of your graduation design. Third to elaborate technical solution, it should be combined with a flow chart, block diagram, schematics, or timing diagrams. Fourth, answering what are the key points and innovations of your graduation project. Fifth, if there are any measures to resolve your scientific or technical issue.

After they got the table I communicated with them about their project every week till to the end of graduation design process, I found that they can't not properly answered the questions for first several weeks, however, after two months they become qualified, and I become aware of their project too, and capable to grasp the direction.

\section{Build Trust with Students}

The students I advised didn't trust me at first, they always complained with their friends and classmates about their young instructor for weeks, however, by every week discussion, we become friends to the end of graduation project, and they got satisfactory results of their project. However there is another problem for a young teacher, the students who were guided by other senior teacher, they feel young teacher is less knowledge when they gave presentation of their graduate project, always answered directly that you have no idea about my project. It is difficult for a young teacher to keep his head when the student said like that, however I changing the way to ask questions, I tried to lead the student from a simpler question to the final question, It make students to find their problems themselves instead of explicitly pointing out.

\section{Graduation Project Benefits from Micro Class}

Micro class refers to taking video and animation as the main carrier, in order to record the teaching process, including both the inside and outside teaching process around a certain knowledge point in order to carry out the whole process of teaching activities. [5] Micro class contains short lessons, teaching design and summarizes the review of teaching resources, which is different from the traditional single resource type, having the characteristics that the teaching time is short, focused, and the new characteristics of small capacity. Micro lesson is as an auxiliary to the classroom teaching of complementary resources, with which students can understand knowledge earnestly, and enrich the method of knowledge acquisition.

Today's teaching mode focuses on PPT interpretation and application of dull courses on complex knowledge points. In the implementation of teaching, the most difficult thing is to make students understand or understand thoroughly the key and difficult points, however the students application ability is low. Micro class because of the characteristics of "short" which can break down complex knowledge, in addition dynamic video can stimulate students' interest in learning. Therefore, the class can be integrated with the course teaching. Micro class can service and improve the teachers "teaching", moreover can promote and develop the students "learning".

In micro teaching mode, teachers can break up throughout the classroom teaching content with micro lesson teaching video, combined with relevant teaching design, auxiliary resources which constitute a true vivid teaching situation, and let the students have a real interest in learning professional knowledge. For instance, in the teaching section of the curriculum and air loss in the principle of automotive engine, an animation for the curriculum period of the automotive engine can be used for motivating the interest of students, in order to let them create a real understanding for the curriculum and air loss in the automotive engine. 
Micro class contains the teaching design, the auxiliary material relevant to the subject matter and the teaching lesson pieces, explains the core knowledge and process demonstrate, etc., can reproduce the teaching details of teacher, which makes students quickly grasp the knowledge, and to let teachers have more time to focus on the cultivation of creative thinking, and make the classroom teaching efficiency be improved. Such as gasoline engine mixture formation and combustion section, the teacher may prior to record a video of micro class about the structure of the gasoline engine and the mixture formation process; with the help of micro tutorial the students in class can beforehand understand the knowledge point. Micro lesson contents, although a single video, have very strong pertinence, will only involves a single knowledge, students in the teaching of the course can feel better to understand what the teachers are teaching them.

Restricted by some objective conditions, the student's knowledge bases are different; the traditional teaching way is very difficult to meet the needs of different students. Micro class capacity is small, which is easy to learn, and can be adjusted according to the teaching requirements, teaching content and the training material resources. Through the integration of micro class and the traditional teaching resources, teaching implementation is not synchronized, which makes up for the defect of traditional teaching and the insufficiency. Students can use mobile terminals such as mobile phones, to perform the study at any time, in order to meet different learning based on different learning levels of demand. For instance, to conduct the interpretation of the mixture formation and combustion process of car engine, the characteristics of mixture formation in combustion gasoline engine take be taken as a micro class within 15 minutes to provide priority to the class teaching, students will have a clear understanding to the mixture formation and combustion, in the class teaching process students can easier accept the complex concept of mixture formation and combustion.

\section{Conclusion}

For a young teacher, it is very common for one teacher to guide at least 7 students for different projects in Chinese university. It is unavoidable to feel at a loss during the process of graduation design at first due to lack of experiences, poor communication skills, and even lack of knowledge. It is suitable to lead them to do it by themselves and keeping in touch with them to go forward together, and make them to get deeper of their project. A young teacher also will confront doubts of students when participate in graduation presentations of graduate students. It is suitable to lead students from a simpler question to the final question which will make students to find their problems themselves instead of explicitly pointing out it. Micro lesson can build a vivid teaching situation and injects new vitality to the teaching. Combining micro lesson method and traditional teaching resources, the teaching result of car engine principle can be improved effectively.

\section{Acknowledgement}

This paper is supported by the National Natural Science Foundation of China (Grant No. 51506038) and project HIT.NSRIF.2015116 and HIT.NSRIF.2016095.

\section{References}

[1] Yanbin Li, Youhua Gao, Xueyan Sun. com Teaching reform of graduate design and production practice based on the combination between campus and enterpris.[J] University education 07 (2016) 31-32.

[2] J.P. Fielding, H. Smith, P.J. Stocking. Cranfield Graduate Aircraft Design Education.[C] 10th AIAA Aviation Technology, Integration, and Operations (ATIO) Conference 13 - 15 September 2010, Fort Worth, Texas, AIAA 2010-9067.

[3] P.J.Stocking. The teaching of aerospace vehicle design at Cranfield University with particular reference to the group design project.[C] Proceeding of IMechE Part G: Journal of Aerospace 
Engineering, 221 (2007) 225-234.

[4] Xuan Zhou, Dongyun Li, Li Jiang, Yang Xu, Hongliang Ge. The existing problems and countermeasures in graduation project of materials major.[J] Science \& Technology Vision, (2016) 146.

[5] C.W.Peng, J.L. Zhou, Y.X. Shi. Fusion of Micro Class with the Automobile Engine Principle Teaching.[J] Agricultural Engineering, 5 (2015) 142-143. 